\title{
Further Clinical Evidence for the Effect of IGF-1 on Hair Growth and Alopecia
}

\author{
Ralph M. Trüeba, b \\ ${ }^{a}$ Center for Dermatology and Hair Diseases Professor Trüeb, Wallisellen, and ${ }^{b}$ University of Zurich, Zurich, \\ Switzerland
}

\section{Established Facts}

- Insulin-like growth factor 1 (IGF-1) has been shown to affect follicular proliferation, tissue remodeling, and the hair growth cycle, as well as follicular differentiation, identifying IGF-1 signaling as an important mitogenic and morphogenetic regulator in hair follicle biology.

- Accordingly, patients with the condition of primary growth hormone $(\mathrm{GH})$ deficiency resulting from defective hormone binding with low IGF-1 (Laron syndrome) show sparse hair growth.

\section{Novel Insights}

- Three patients with complaint of thin hair are presented with evidence of GH/IGF-1 deficiency due to primary GH deficiency or hypophyseal surgery.

- Hypotrichosis in primary GH deficiency, and a lack of response of androgenetic-type alopecia to the respective treatments in patients who had undergone hypophyseal surgery, provide further evidence for an effect of IGF-1 on hair growth and alopecia.

\section{Keywords}

IGF-1 · Growth hormone deficiency · Laron syndrome ·

Hypophysectomy · Hypotrichosis · Androgenetic alopecia

\begin{abstract}
Observations on the Laron syndrome originally offered the opportunity to explore the effect of insulin-like growth factor 1 (IGF-1) deficiency on human hair growth and differentiation. According to its expression in the dermal hair papilla, IGF-1 is likely involved in reciprocal signaling. It has been shown to affect follicular proliferation, tissue remodeling, and the hair growth cycle, as well as follicular differentiation,
\end{abstract}

identifying IGF-1 signaling as an important mitogenic and morphogenetic regulator in hair follicle biology. Of all the cytokines or growth factors that have been postulated to play a role in hair follicles, ultimately IGF-1 is known to be regulated by androgens. Accordingly, dermal papillary cells from balding scalp follicles were found to secrete significantly less IGF-1 than their counterparts from nonbalding scalp follicles. Herein, hypotrichosis in primary growth hormone deficiency, and a lack of response of female and male androgenetic-type alopecia to treatment with topical minoxidil and oral finasteride in patients who had undergone surgical resection of the pituitary gland, provide further evidence for an effect of IGF-1 on hair growth and alopecia.

(c) 2017 S. Karger AG, Base

\section{KARGER}

(c) 2017 S. Karger AG, Basel

E-Mail karger@karger.com

www.karger.com/sad
Ralph M. Trüeb, MD

Center for Dermatology and Hair Diseases Professor Trüeb Bahnhofplatz 1A

CH-8304 Wallisellen (Switzerland)

E-Mail r.trueeb@derma-haarcenter.ch 
Nature is nowhere accustomed more openly to display her secret mysteries than in cases where she shows traces of her workings apart from the beaten path; nor is there any better way to advance the proper practice of medicine than to give our minds to the discovery of the usual law of Nature by careful investigation of cases of rare forms of disease. For it has been found in almost all things, that what they contain of useful or applicable nature is hardly perceived unless we are deprived of them, or they become deranged in some way. William Harvey (1578-1657)

\section{Introduction}

Based on observations in Israel dating back to 1958, Laron et al. [1] in 1966 reported a peculiar type of dwarfism characterized by grossly impaired growth despite normal or raised serum levels of growth hormone (GH). Further investigations revealed that the disorder is associated with mutations in the gene for the GH receptor that result in defective hormone binding or a reduced efficiency of dimerization of the receptor after hormone occupancy, as well as exceptionally low levels of insulinlike growth factor 1 (IGF-1) [2]. The condition has an autosomal recessive pattern of inheritance, and the majority of reported cases have been in people of Semitic origin. While numerous Laron syndrome patients are found in Israel among the country's diverse population composed of Jews from around the world, a disproportionate number of sufferers have also been detected in remote villages of Ecuador [3,4]; these sufferers are descended from colonial-era New Christian conversos of Sephardic Jewish origin who had been compelled to convert to Catholicism back in Spain and had migrated to Ecuador during the Spanish Conquest as a result of the Inquisition [5].

Besides an abnormally short stature, physical symptoms of the syndrome include a prominent forehead, depressed nasal bridge, underdevelopment of the mandible, and truncal obesity [6]. Only in 2004, the condition of the hair in Laron syndrome patients was reported by Lurie et al. [7], who suggested it to offer a unique model for exploring the effect of IGF-1 deficiency on human hair. Affected children had sparse hair growth and frontal recession. The hair was thin and easy to pluck. Young adults had various degrees of alopecia that was more pronounced in males. Despite these signs of early aging, graying of the hair was delayed and reduced.

Herein, 3 patients with evidence of GH/IGF-1 deficiency are presented with the complaint of thin hair.

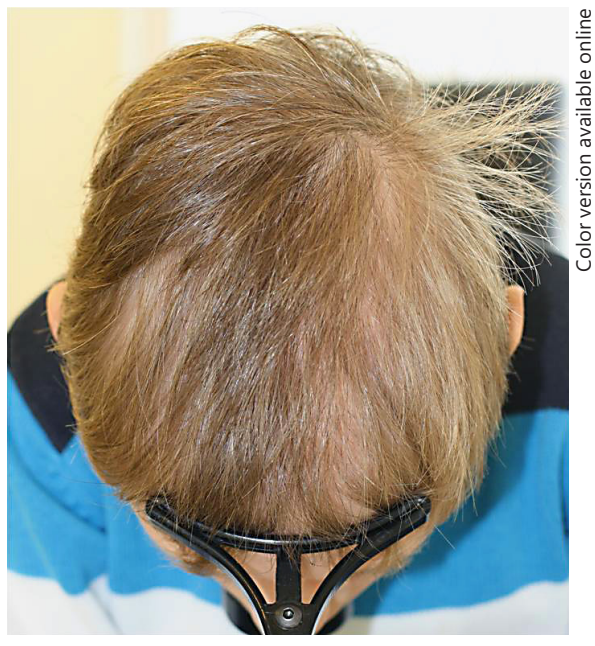

Fig. 1. Hypotrichosis in a boy with primary growth hormone deficiency.

\section{Case Reports}

Case 1

A 10-year-old boy was referred by his dermatologist because of hypotrichosis since early childhood. The child was diagnosed with primary $\mathrm{GH}$ deficiency by the pediatric endocrinologist, and substituted since 4 years with $0.9 \mathrm{mg} /$ day and $10 \mathrm{mg}$ on day 11 of treatment with recombinant human GH (Norditropin ${ }^{\circledR}$ FlexPro ${ }^{\circledR} 10 \mathrm{mg}$; Novo Nordisk Pharma AG). Clinical inspection revealed a diffuse pattern of thin hair with decreased density (Fig. 1), and no other conspicuous findings related either to the condition of the hair shafts or to the dermoscopic examination. There were no associated anomalies. His height and body weight in relation to his age were on the lower percentile of normal. Despite recombinant human GH substitution, the IGF-1 level was found to be in the lower range of normal $(19.6 \mathrm{nmol} / \mathrm{L})$. Therefore, the dosage of GH was increased to $1.0 \mathrm{mg} /$ day and 10 mg on day 10 of therapy. An increase in body height was noted. The condition of the hair neither improved nor deteriorated any further.

\section{Case 2}

A 62-year-old woman was referred for progressing thinning of the hair in the crown area. Clinical examination revealed centroparietal thinning of the hair with widening of the central part's width and significant diversity of hair shaft diameters on dermoscopy. A hair pluck was consistent with the diagnosis of androgenetic alopecia. The family history revealed late-onset patterned hair loss in the patient's mother. Twenty-two years earlier the patient had been diagnosed with a hypophyseal tumor and had undergone hypophysectomy with postoperative radiotherapy. She was substituted with thyroid hormone, cortisone, and estrogen in combination with cyproterone acetate. She was diagnosed with female pattern hair loss and treated with $2 \%(\mathrm{Al}-$ opexy ${ }^{\circledR}$; Pierre Fabre Suisse S.A.) and later $5 \%$ topical minoxidil solution b.i.d. over 5 years without success (Fig. 2). 
Fig. 2. Lack of response of female androgenetic-type alopecia to topical minoxidil in a patient who underwent surgical resection of the hypophyseal gland for a tumor. Before (a) and after (b) 3 years of treatment.

Fig. 3. Lack of response of male androgenetic-type alopecia to combination therapy with oral finasteride and topical minoxidil in a patient who underwent hypophyseal surgery for a Rathke cleft cyst. Before (a) and after (b) 4 years of treatment.
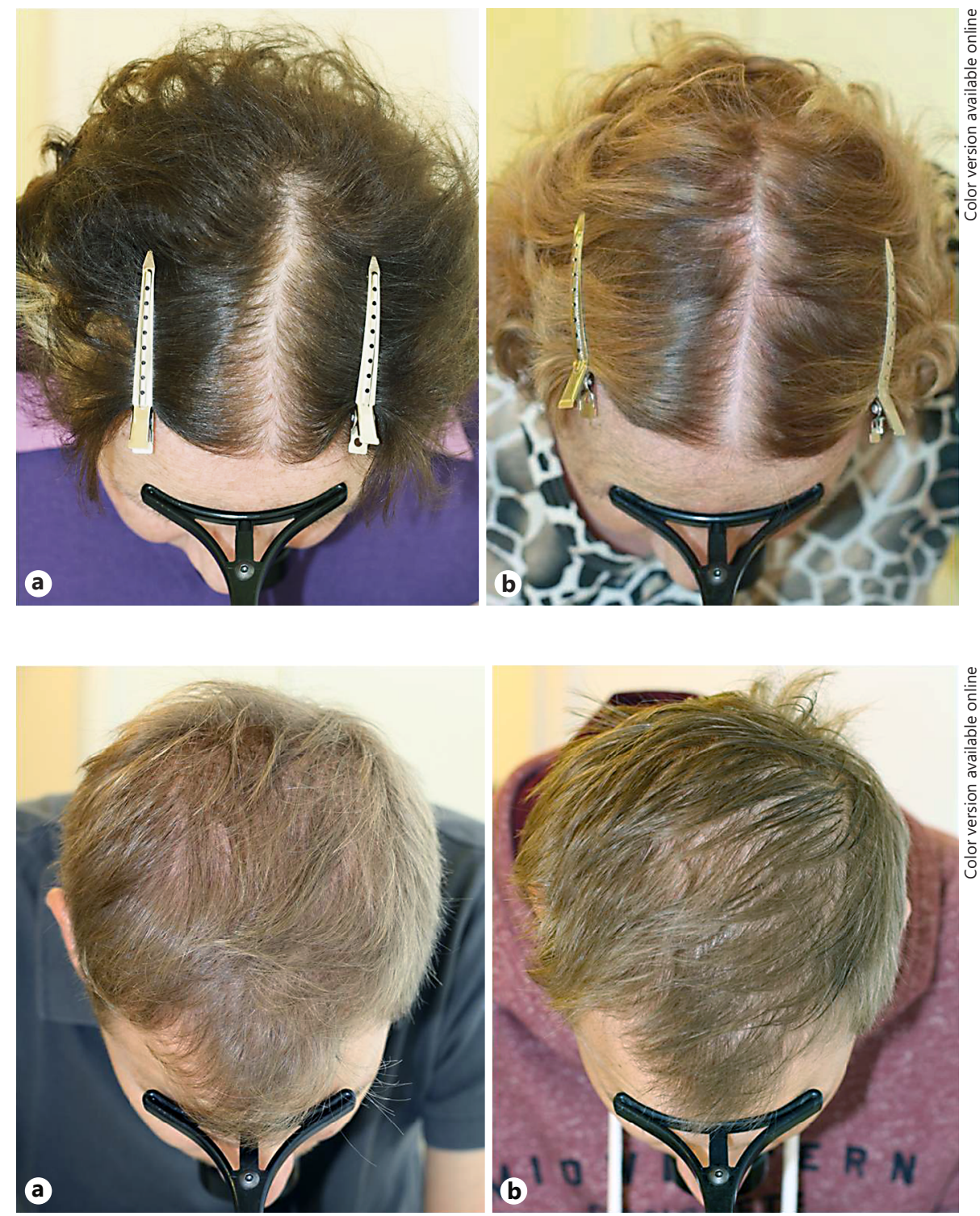

Case 3

A 26-year-old man was referred for thinning of the hair in the crown area with regression of the temporal hairline. Clinical examination revealed both symmetrical bitemporal regression of the hairline and centroparietal thinning of the hair with significant diversity of hair shaft diameters and peripilar signs on dermoscopy. A diagnosis of male androgenetic alopecia was made and the patient was given $1 \mathrm{mg}$ oral finasteride (Propecia ${ }^{\circledR}$; Merck Sharp \& Dohme AG) for 5 years. Since his symptoms did not improve, the serum dihydrotestosterone level was determined with the objective of possibly switching to oral dutasteride depending on the result. Since the dihydrotestosterone level was $0.31 \mathrm{nmol} / \mathrm{L}$ (normal range: $1.05-2.98 \mathrm{nmol} / \mathrm{L}$ ) and therefore adequately suppressed by the ongoing oral finasteride therapy, the patient was alternatively given topical $10 \%$ minoxidil sulfate solution once daily in addition to oral finasteride therapy. After another 2 years of com- bined therapy, there was again no success (Fig. 3). An extended personal history revealed that the patient had undergone hypophyseal surgery 25 years earlier for a Rathke cleft cyst. Therefore, the serum IGF-1 serum level was determined, and with $3.0 \mathrm{nmol} / \mathrm{L}$ (normal range: $10.4-31.0 \mathrm{nmol} / \mathrm{L}$ ) found to be significantly decreased.

\section{Discussion}

The hair follicle is subject to constant turnover in the course of perpetual cycles through stages of proliferation in anagen, involution in catagen, and resting in telogen, with regeneration in the successive hair cycle. The con- 
trols that underlie the hair cycle reside within the hair follicle itself, and are believed to result from changes in the intra- and perifollicular expression of specific regulatory molecules and their receptors $[8,9]$. Circumstantial evidence suggests that the dermal hair papilla, which is composed of specialized fibroblasts located at the base of the hair follicle, determines hair follicle growth characteristics. The dermal papilla cells can secrete a number of cytokines, and growth factors that influence growth in the diverse compartments of the hair follicle [10]. While the molecular basis for these interactions remains largely unexplored, there is circumstantial evidence that IGF-1 signaling is involved in the hair growth cycle and the differentiation of hair shafts [11].

Accordingly, Lurie et al. [7] investigated the effect of a rare form of genetic IGF-1 deficiency on hair growth by sampling the hair of patients with Laron syndrome, and found alopecia and structural hair defects, including pili torti et canaliculi [12], grooving, tapered hair, and trichorrhexis nodosa, further corroborating the regulatory function of IGF-1 in hair growth and differentiation [13].

Surprisingly little has been published on the effect of acquired GH/IGF-1 deficiency on hair, specifically following transsphenoidal adenomectomy [14] or with somatostatin analog therapy for acromegaly $[15,16]$. In one study, of 484 patients who underwent transsphenoidal adenomectomy for acromegaly, 263 (54\%) noticed varying degrees of hair loss between 3 and 6 months after surgery. The degree of alopecia was minimal in 50 patients (10\%), moderate in 117 patients (24\%), and severe in 96 patients (20\%). Postoperative hair loss was significantly more common among female patients, cured patients, and patients with severe postoperative GH deficiency. Among the 263 patients, full recovery was reported by 85 patients (32\%), partial recovery by 88 patients (34\%), and practically no recovery by 90 patients (34\%). A lack of hair recovery was significantly more common among male patients, or among patients with severe hair loss [14].

Nevertheless, in their original publication on methods of hair loss evaluation in patients with endocrine disorders, Olszewska et al. [17] reported that most patients with endocrine disorders present with diffuse nonscarring alopecia, and that hair loss may be a symptom in $\mathrm{GH}$ deficiency. Also Trüeb [18] affirms that with respect to the relationship between hormones and hair growth, the role of androgens in androgenetic alopecia and hirsutism might be the best acknowledged, but clinical observations of hair conditions involving hormones beyond the androgen horizon have determined their role in the reg-

Effect of IGF-1 on Hair Growth and Alopecia ulation of hair growth and interrelationships with androgens, specifically estrogens, prolactin, thyroid hormone, $\mathrm{GH}$, and IGF-1. Ultimately, the question is raised whether the hypothesis that a causal relationship exists between the age-related reduction in circulating hormones and organ function also applies to hair and the aging of hair [19].

Indeed, Edmund Chein [20] from the Palm Springs Life Extension Institute originally claimed an improvement of hair thickness and structure in $38 \%$, darkening of hair in some, and increased hair growth in few of the patients undergoing recombinant $\mathrm{GH}$ treatment in the course of hormonal antiaging protocols. Antiaging medicine, also known as life extension science, is the study of slowing down or reversing the processes of aging to extend both the maximum and the average life span. The sale of purported antiaging products such as hormone replacement, including $\mathrm{GH}$, has become a lucrative global industry, with the US market generating about USD 50 billion of revenue a year [21]. However, the use of such products has not been proven to be either effective or safe [22]. Specifically, alterations in GH/IGF-1 signaling with reductions in these somatotrophs appear to increase the life span in animal models [23]. While increases in GH and IGF-1 are beneficial during adolescence, studies relating the GH and IGF-1 status to longevity provide inconsistent evidence as to whether decreased or high levels of these hormones are beneficial or detrimental to longevity. It remains difficult to reconcile the largely protective effects of GH/IGF-1 deficiency on longevity in animals with the inconsistent or deleterious effects of low levels or declining GH/IGF-1 during human aging. Moreover, people with IGF-1 deficiency in Laron syndrome have strikingly low rates of diabetes and cancer [24].

Alternatively, investigations are conducted on the topical application of IGF-1, inasmuch as dermal papillary cells from balding scalp follicles have been found to secrete less IGF-1 than their counterparts from nonbalding scalp follicles [25]. Moreover, low circulating IGF-1 levels have been associated with hair loss in middle-aged women [26].

Platelet-rich plasma (PRP) is blood plasma that has been enriched with platelets. As a concentrated source of autologous platelets, PRP contains and releases through degranulation several growth factors and cytokines, including IGF-1. PRP has (again) gained popularity among a limited number of dermatologists with a primary commercial interest, though the use and clinical validation of the method for diverse dermatologic conditions is still in 
the early stages. The results of basic science and preclinical trials have yet to be confirmed in large-scale controlled clinical trials $[27,28]$.

Currently, commercial products containing IGF-1 exist for transdermal application using a dermaroller, usually in combination with other growth factors such as bFGF (basic fibroblast growth factor) and VEGF (vascular endothelial growth factor), copper peptide, hyaluronic acid, coenzyme $\mathrm{Q}$, vitamins $\mathrm{B} 3, \mathrm{~B} 6$, and $\mathrm{B} 5$, and amino acids (arginine and lysine). However, their efficacy has not yet been substantiated in clinical studies published in peer-reviewed scientific publications. Alternatively, liposomal IGF-1 and VEGF in topical gel formulations to promote hair growth have been studied in the hamster (Mesocricetus auratus); their efficacy was determined by dermoscopic analysis of hair density and microscopic analysis of the hair diameter. The hair was found to grow faster and thicker in the 3\% liposomal IGF-1 and VEGF groups than in the respective $1 \%$ or control groups [29].

For now, the role of IGF-1 in hair growth and alopecia is to be acknowledged, based on the observations among others [14-16] - that are presented herein re- garding hypotrichosis in primary $\mathrm{GH}$ deficiency, and the lack of response of female and male androgenetic-type alopecia to treatment with topical minoxidil and oral finasteride, respectively, in patients with a history of hypophyseal surgery. That the hypotrichosis in primary $\mathrm{GH}$ deficiency did not respond to the increase in dosage of GH therapy may point to the necessity of early diagnosis and substitution. Whether GH and IGF-1 have any role in the treatment of alopecia - either systemically or topically, and either with respect to or irrespective of the measured serum levels - yet remains to be elucidated in studies addressing their efficacy, safety, and cost-benefit ratio.

\section{Statement of Ethics}

The author has no ethical conflicts to disclose. The patients' consent has been obtained.

\section{Disclosure Statement}

The author has no disclosure to report.

\section{References}

1 Laron Z, Pertzelan A, Mannheimer S: Genetic pituitary dwarfism with high serum concentration of growth hormone - a new inborn error of metabolism? Isr J Med Sci 1966;2: 152-155.

2 Laron Z: Laron syndrome (primary growth hormone resistance or insensitivity): the personal experience 1958-2003. J Clin Endocrinol Metab 2004;89:1031-1044.

3 Rosenbloom AL, Guevara-Aguirre J, Rosenfeld RG, Fiedler PJ: The little women of Loja - growth hormone-receptor deficiency in an inbred population of southern Ecuador. N Engl J Med 1990;323:1367-1374.

4 Guevara-Aguirre J, Rosenbloom AL, Vaccarello MA, Fielder PJ, de la Vega A, Diamond FB Jr, Rosenfeld RG: Growth hormone receptor deficiency (Laron syndrome): clinical and genetic characteristics. Acta Paediat Scand Suppl 1991;377:96-103.

5 Rosenbloom AL, Guevara-Aguirre J, Rosenfeld RG, Francke U: Growth hormone receptor deficiency in Ecuador. J Clin Endocrinol Metab 1999;84:4436-4443.

6 Laron Z, Anin S, Klipper-Aurbach Y, Klinger B: Effects of insulin-like growth factor on linear growth, head circumference, and body fat in patients with Laron-type dwarfism. Lancet 1992;339:1258-1261.
7 Lurie R, Ben-Amitai D, Laron Z: Laron syndrome (primary growth hormone insensitivity): a unique model to explore the effect of insulin-like growth factor 1 deficiency on human hair. Dermatology 2004;208:314-318.

8 Paus R, Cotsarelis G: The biology of hair follicles. N Engl J Med 1999;341:491-497.

9 Paus R, Müller-Röver S, Botchkarev VA: Chronobiology of the hair follicle: hunting the "hair cycle clock." J Invest Dermatol Symp Proc 1999;4:338-345.

10 Stenn KS, Combates NJ, Eilertsen KH, Gordon JS, Pardinas JR, Parimoo S, Prouty SM: Hair follicle growth controls. Dermatol Clin 1996; 14:543-558.

11 Weger N, Schlake T: IGF-I signalling controls the hair growth cycle and the differentiation of hair shafts. J Invest Dermatol 2005;125: 873-882.

12 Trüeb RM, Spycher MA, Schumacher F, Burg G: Pili torti et canaliculi in ectodermal dysplasia (in German). Hautarzt 1994;45:372-377.

13 Ben Amitai D, Lurie R, Laron Z: I-GF-1 signalling controls the hair growth cycle and the differentiation of hair shafts. J Invest Dermatol 2006;126:2135; author reply 2135-2136.
14 Yamada S, Fukuhara N, Nishioka H, Yamaguchi-Okada M, Takeshita A, Takeuchi Y: Scalp hair loss after transsphenoidal adenomectomy in patients with acromegaly. Clin Endocrinol (Oxf) 2013;79:386-393.

15 Nakauchi Y, Kumon Y, Yamasaki H, Tahara K, Kurisaka M, Hashimoto K: Scalp hair loss caused by octreotide in a patient with acromegaly: a case report. Endocr J 1995;42:385389.

16 Alvarez-Escola C, Cárdenas-Salas JJ, Pelegrina B, Sanz-Valtierra A, Lecumberri B: Severe scalp hair loss in a female patient with acromegaly treated with lanreotide autogel after unsuccessful surgery. Clin Case Rep 2015;3: 945-948.

17 Olszewska M, Warszawik O, Rakowska A, Słowińska M, Rudnicka L: Methods of hair loss evaluation in patients with endocrine disorders. Endokrynol Pol 2010;61:406-411.

18 Trüeb RM: Hormones and hair growth (in German). Hautarzt 2010;61:487-495.

19 Trüeb RM: Pharmacologic interventions in aging hair. Clin Interv Aging 2006;1:121-129.

20 Chein E: Age Reversal, from Hormones to Telomeres. Salt Lake City, WorldLink Medical Publishing, 1998. 
21 Japsen B: AMA report questions science behind using hormones as anti-aging treatment. The Chicago Tribune, June 15, 2009 (retrieved July 17, 2009).

22 Sattler FR: Growth hormone in the aging male. Best Pract Res Clin Endocrinol Metab 2013;27:541-555.

23 Bartke A, Brown-Borg H: Life extension in the dwarf mouse. Curr Top Dev Biol 2004;63: 189-225.

24 Guevara-Aguirre J, Balasubramanian P, Guevara-Aguirre M, Wei M, Madia F, Cheng CW, Hwang D, Martin-Montalvo A, Saavedra J, Ingles $\mathrm{S}$, de Cabo $\mathrm{R}$, Cohen $\mathrm{P}$, Longo VD: Growth hormone receptor deficiency is asso- ciated with a major reduction in pro-aging signaling, cancer, and diabetes in humans. Sci Transl Med 2011;3:70ra13.

25 Panchaprateep R, Asawanonda P: Insulin-like growth factor-1: roles in androgenetic alopecia. Exp Dermatol 2014;23:216-218.

26 Noordam R, Gunn DA, van Drielen K, Westgate G, Slagboom P, de Craen AJ, van Heemst D: Both low circulating insulin-like growth factor-1 and high-density lipoprotein cholesterol are associated with hair loss in middleaged women. Br J Dermatol 2016;175:728734.

27 Giordano S, Romeo M, Lankinen P: Plateletrich plasma for androgenetic alopecia: does it work? Evidence from meta analysis. J Cosmet Dermatol 2017, Epub ahead of print.

28 Ayatollahi A, Hosseini H, Gholami J, Mirminachi B, Firooz F, Firooz A: Platelet rich plasma for treatment of non-scarring hair loss: systematic review of literature. J Dermatolog Treat 2017, Epub ahead of print.

29 Castro RF, Azzalis LA, Feder D, Perazzo FF, Pereira EC, Junqueira VB, Rocha KC, Machado CD, Paschoal FC, Gnann LA, Fonseca FL: Safety and efficacy analysis of liposomal insulin-like growth factor- 1 in a fluid gel formulation for hair-loss treatment in a hamster model. Clin Exp Dermatol 2012;37: 909-912. 